32. Kals, E., Schumacher, D. and Montada, L., Emotional affinity toward nature as a motivational basis to protect nature. Environ. Behav., 1999, 31(2), 178-202.

33. Schultz, P. W., The structure of environmental concern: concern for self, other people, and the biosphere. J. Environ. Psychol., 2001, 21(4), 327-339.

34. Kyle, G., Graefe, A. and Manning, R., Testing the dimensionality of place attachment in recreational settings. Environ. Behav., 2005, 37(2), 153-177.

35. Hammitt, W. E., Backlund, E. A. and Bixler, R. D., Place bonding for recreation places: conceptual and empirical development. Leisure Stud., 2006, 25(1), 17-41.

36. Dey, P. and Chattopadhyay, S., Impact of socio-economic status on place and dwelling attachment. Int. J. Hous. Sci. Appl., 2017, 41(2), 89-100.

37. Ofoegbu, C., Chirwa, P. W., Francis, J. and Babalola, F. D., Socio-economic factors influencing household dependence on forests and its implication for forest-based climate change interventions. South. Forest., 2017, 79(2), 109-116.

38. Tynsong, H., Tiwari, B. K. and Dkhar, M., Contribution of NTFPs to cash income of the War Khasi community of southern Meghalaya, North-East India. For. Stud. China, 2012, 14(1), 47-54.

39. Padoch, C., Coffey, K., Mertz, O., Leisz, S. J., Fox, J. and Wadley, R. L., The demise of swidden in Southeast Asia? Local realities and regional ambiguities. Geogr. Tidsskr-Den., 2007, 107(1), 29-41.

40. Mishra, S., Mazumdar, S. and Suar, D., Place attachment and flood preparedness. J. Environ. Psychol., 2010, 30(2), 187-197.

41. Fernandes, W., Look (act) East policy: with or through the Northeast. In Mainstreaming the Northeast in India's Look and Act East Policy, Palgrave Macmillan, Singapore, 2018, pp. 233-251.

42. Aayog NITI, Shifting Cultivation: Towards a Transformational Approach, 2018; https://niti.gov.in/writereaddata/files/document publication/doc3.pdf

43. Tripathi, P., Tribes and forest: a critical appraisal of the tribal forest right in India. Res. J. Soc. Sci. Manage., 2016, 6(06), 1-8.

44. Singh, B. P., Biodiversity, tribal knowledge and life in India Environ. Soc. Psychol., 2017, 2(1), 1-10.

45. Chaudhry, P., Dollo, M., Bagra, K. and Yakang, B., Traditional biodiversity conservation and natural resource management system of some tribes of Arunachal Pradesh, India. Interdisc. Environ. Rev., 2011, 12(4), 338-348.

46. Sangma, R. C., Festivals and ceremonies of Garo. Garo J., 2018; https://garojournal.com/festivals-ceremonies-garos/

47. Chapin III, F. S., Mark, A. F., Mitchell, R. A. and Dickinson, K. J., Design principles for social-ecological transformation toward sustainability: lessons from New Zealand sense of place. Ecosphere, 2012, 3(5), 1-22.

48. Potschin, M. and Haines-Young, R., Landscapes, sustainability and the place-based analysis of ecosystem services. Landsc. Ecol., 2013, 28(6), 1053-1065.

ACKNOWLEDGEMENTS. This study is a part of a project funded by the Indian Council of Agricultural Research, New Delhi. We thank the respondents, tribals and key informants for their participation.

Received 2 August 2020; accepted 5 November 2020

doi: $10.18520 / \mathrm{cs} / \mathrm{v} 120 / \mathrm{i} 1 / 215-220$

\section{Assessment of colour changes in Lonar lake, Buldhana district, Maharashtra, India using remote sensing data}

\author{
Anurag Mishra, K. Abdul Hakeem*, \\ V. V. Rao, P. V. N. Rao and Santanu Chowdhury \\ National Remote Sensing Centre, Indian Space Research Organisation, \\ Hyderabad 500 037, India
}

This communication presents results of a preliminary study to understand and assess the colour changes in Lonar lake, Buldhana district, Maharashtra, India, using remote sensing data of recent years (2019 and 2020). In addition, the study has utilized IMD gridded weather data and spectral profiles of algal pigments from the published literature. In order to verify whether the colour change is a cyclic event, long-term satellite data of Landsat 8-OLI and Sentinel 2-MSI sensors from 2014 onwards were analysed using spectral response in red and green bands. It was observed that even though a cyclic pattern exists, the colour change events occurred only during the 2019 and 2020 periods. The present analysis showed a change in colour of the lake from green to brown twice during April-June 2019. However, in 2020, there was a change in colour of the lake from green to brown and eventually to pinkish-red, which was not observed earlier. Rainfall and temperature were used to identify possible causes of abiotic stress on algae population of the lake. The study observed light rainfall and reduction in temperature just prior to the colour change event during both the years. In the absence of field data, the published literature on absorption spectra of different algal pigments was reviewed to identify pigments causing brown- and red-coloured appearance of the lake. Though cause of stress on the algae population is not known and is to be precisely identified by field surveys, the change in colour of Lonar lake appears to be caused by pigment(s), like phycoerythrin and carotenoids. However, this needs to be verified in the ground through water quality analysis.

Keywords: Colour changes, lake water, pigments, remote sensing, water quality analysis.

IN the second week of June 2020, several print and electronic media reported change in colour of Lonar lake, Buldhana district, Maharashtra, India ${ }^{1,2}$ from green to pink. This was attributed primarily to the presence of algae in saline water of the lake. It was also reported that though change in colour of the lake had been observed in the past, however, the extreme tone of red colour was witnessed this year. The National Remote Sensing Centre (NRSC), Hyderabad initiated a quick preliminary study to assess the change in colour of this lake using remote

*For correspondence. (e-mail: abdulhakeem_k@nrsc.gov.in) 


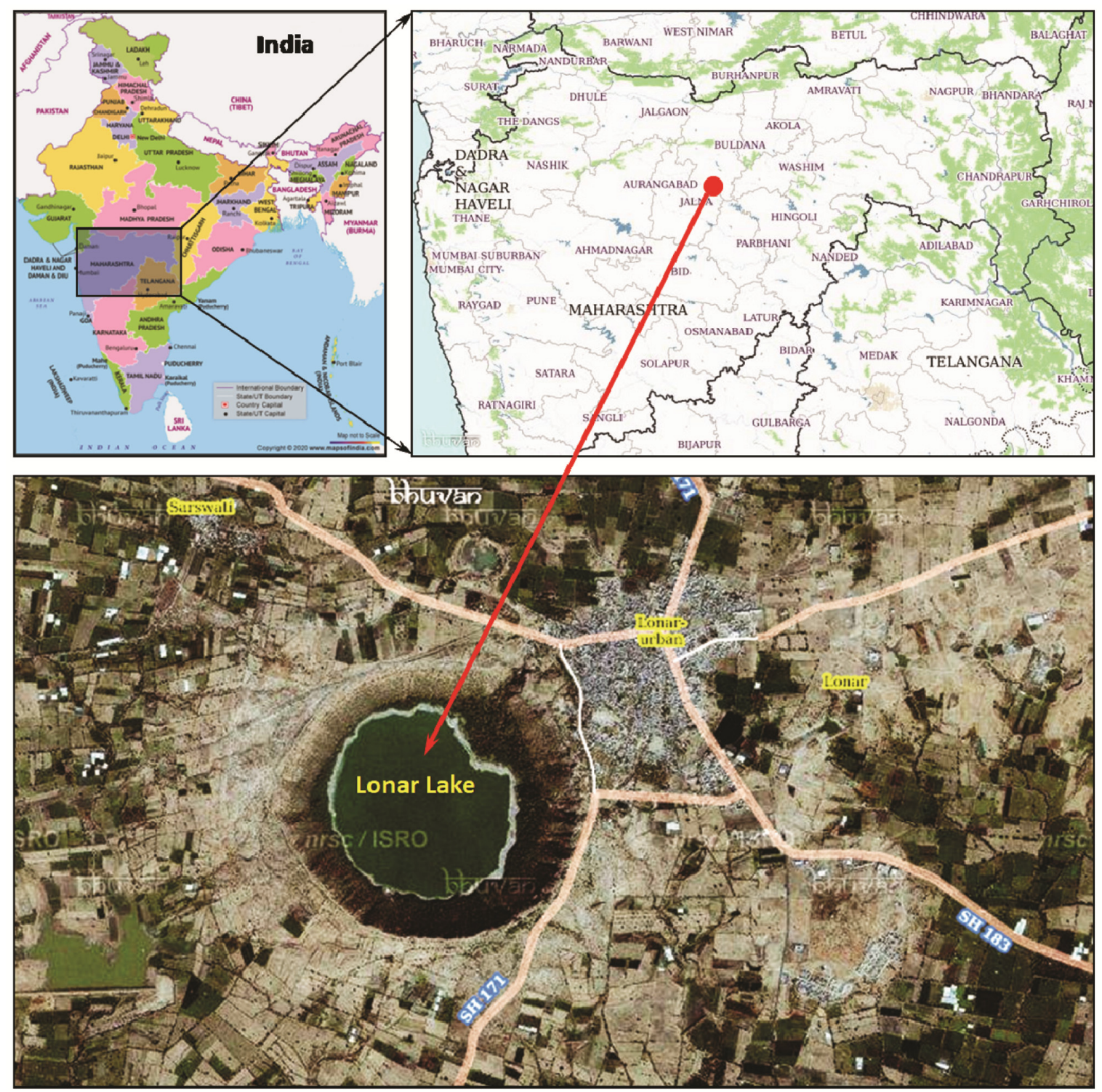

Figure 1. Location map of Lonar lake, Buldhana, Maharashtra, India. (Source: Maps of India and ISRO Bhuvan.).

sensing data. The objective of this study was to understand the dynamics associated with colour change of Lonar lake during recent years (2019 and 2020). The results of the analysis are presented here.

The Lonar lake (Figure 1) was formed due to meteorite impact in the Deccan basalts around 52,000 \pm 6000 years $\mathrm{ago}^{3}$. The crater is a near circular depression with rim-torim diameter of about $1880 \mathrm{~m}$ and depth of about $135 \mathrm{~m}$. These dimensions make it the third largest crater in the world $^{3,4}$. Its ecosystem has developed as closely as saline and alkaline in nature with mean diameter about $1.2 \mathrm{~km}$.

Several studies have reported the presence of bluegreen algae in Lonar lake. The lake is highly eutrophic, where Cyanophyceae (blue-green algae) dominates the total phytoplankton biomass ${ }^{4}$. Among the Cyanophyceae, Spirulina platensis is the major species which generates the dense floating blooms ${ }^{5}$. Planktothrix agardhii is also seen to be dominating in some blooms. The blue-green algal bloom in Lonar lake is responsible for absorption of light due to its pigments. The eutrophication of this lake takes place due to sewage discharge from Lonar town ${ }^{6}$. Members of the class Cyanophyceae are commonly known as blue-green algae. The name is given due to the dominant pigment, c-phycocyanin, and blue-green pigment. In addition, chlorophyll, phycoerythrin, and carotenoids (beta-carotene and xanthophyll) are also present. $S$. platensis which is the dominant algae in Lonar lake generally has pigments like carotenes, chlorophyll- $a$ and phycocyanin ${ }^{7}$.

In order to understand the temporal dynamics of colour changes, multispectral, medium resolution, cloud-free images of Multi Spectral Instrument (MSI) on-board 


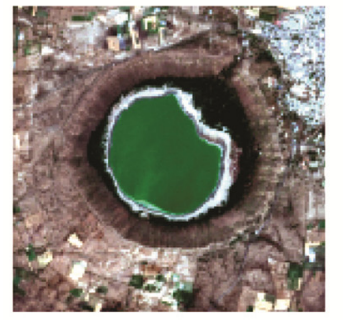

22 March 2020

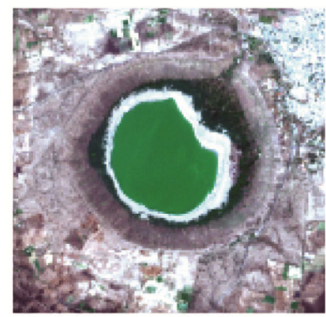

6 May 2020

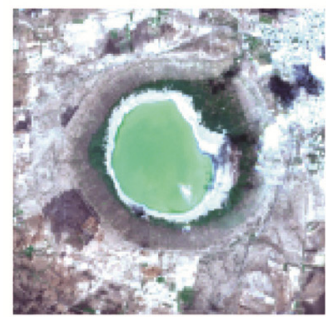

31 May 2020

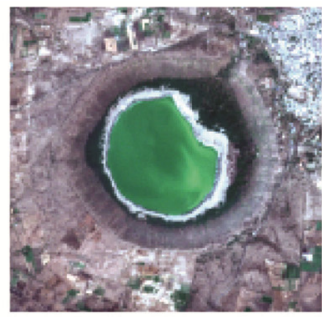

11 April 2020

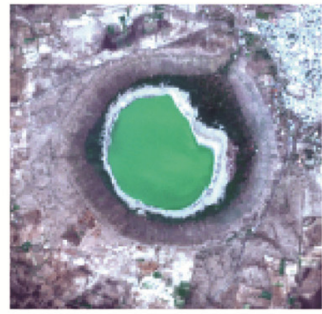

16 May 2020

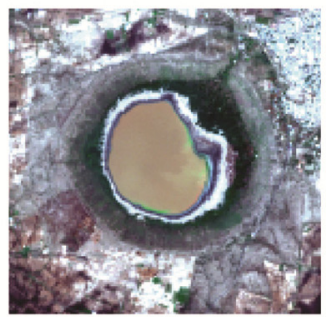

5 June 2020

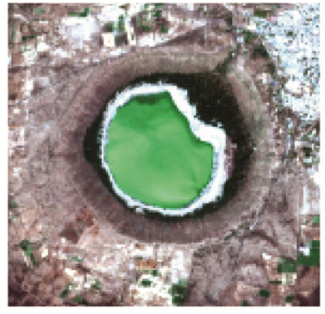

21 April 2020

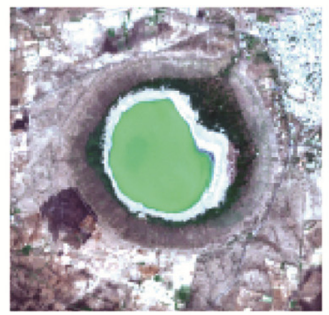

26 May 2020

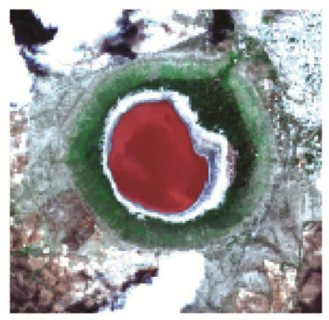

10 June 2020

Figure 2. Natural colour composite images of Lonar lake during summer 2020.

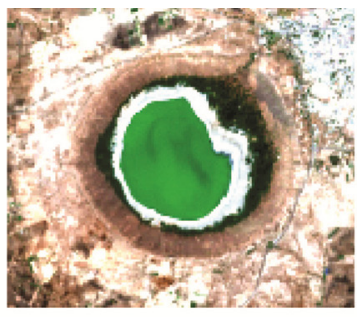

27 May 2019

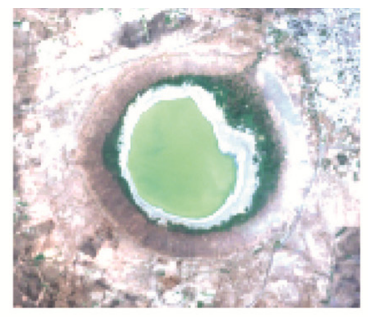

6 June 2019

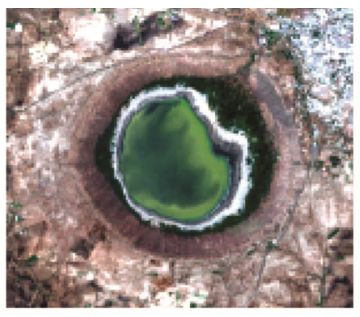

11 June 2019

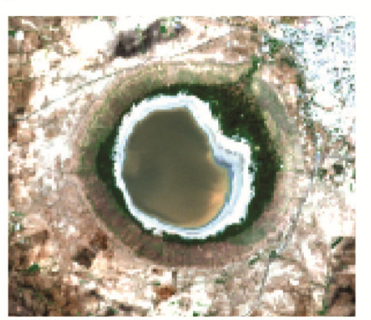

16 June 2019

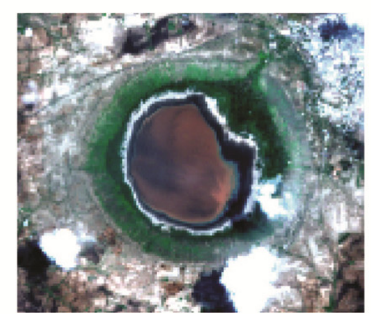

26 June 2019

Figure 3. Natural colour composite images of Lonar lake during summer 2019.

Sentinel $2 \mathrm{~A} / 2 \mathrm{~B}$ were processed to visualize change in colour of the lake. These images were used for visual interpretation as well as to obtain water spectra. This will help in understanding the nature of constituents of the lake which affect its overall spectral response. Images from the MSI sensor of Sentinel 2A/2B were processed from the third weak of March to 10 June 2020. Figure 2 shows images of Lonar lake in natural colour composite, obtained using 665, 560 and $490 \mathrm{~nm}$ bands of Sentinel 2 MSI through the red, green and blue channels respectively. 
It is clearly observed from these images that in summer 2020, colour of the lake was green during March-April, it turned bright green during May. The colour of the lake further changed to brown in the first week of June and eventually turned red during the second week of June.

In order to understand whether the phenomenon of colour change is an annual event, satellite images taken during 2019 summer were also analysed. Figure 3 shows the images of Lonar lake during summer 2019. The images evidently show a colour change from green to reddish-brown during the second fortnight of June 2019.

The following observations are drawn based on Figures 2 and 3, which show change in colour of the lake during 2019 and 2020 respectively.

(i) The change in colour of the lake from green to brown was observed in the first week of June ( 5 June 2020 image) in 2020 and the same was observed in the second fortnight of June (16 June 2019 image) in 2019.

(ii) Though red hue was observed in the lake on 26 June 2019 , it was less intense compared to red colour of the lake on 10 June 2020.

The colour of a water body is largely determined by the biophysical properties of its constituents. The constituents such as colour dissolved organic matter (CDOM) and pigments found in algae largely influence the absorption of solar energy in different regions of the electromagnetic spectrum. The surface reflectance data from MSI were used to derive spectra of Lonar lake on different dates (both pre- and post-) when colour change was reported. The first eight bands of MSI with central wavelengths (443, 495, 560, 665, 705, 740, 782 and $842 \mathrm{~nm})$ were used to plot water spectra on different dates. Figure 4 shows spectral response of water of Lonar lake during summer 2020. The shaded areas in the figure span spectral regions of different bands of MSI.

The water spectra in black colour belong to dates when colour of the water body was green. These spectra have

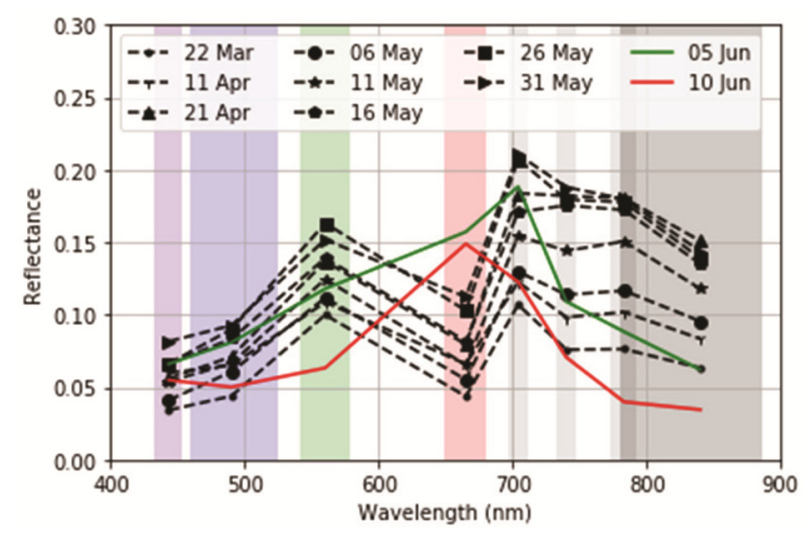

Figure 4. Water spectra of Lonar lake during summer 2020. similar spectral response with absorption dip in the red region $(665 \mathrm{~nm})$ and maximum reflectance in either green $(560 \mathrm{~nm})$ or red-edge $(705 \mathrm{~nm})$ region. These types of spectral characteristics indicate dominance of chlorophyll- $a$ among the algae populations of Lonar lake imparting green appearance to it. Similar spectral response was observed in a study on Lake Bogoria, which is a saline-alkaline lake in the Kenyan Rift Valley, known for supporting blooms of cyanobacteria ${ }^{8}$. It has been observed that increasing chlorophyll- $a$ concentration is related to increase in reflectance at 700-710 nm region ${ }^{9}$. In addition, when chlorophyll- $a$ concentration is very high, reflectance in the red-edge-near infrared (NIR) region (700-850 nm) becomes comparable to reflectance in the visible region (400-700 nm). Moreover, absorption in the blue $(443 \mathrm{~nm})$ and red $(670-680 \mathrm{~nm})$ regions is a distinct feature of chlorophyll- $a$.

In Figure 4, though water spectra during March-May 2020 seem to be dominated by spectral response of chlorophyll- $a$, a deviation is seen on 5 June 2020 (green solid line) and 10 June 2020 (red solid line). The brown appearance of the lake on 5 June 2020 is explained by lower reflectance in all the spectral bands, except in the rededge region in comparison with spectral response during March to May. Similarly, spectral response on 10 June 2020 shows lower reflectance, except peak reflectance in the red region which is associated with red appearance of the lake. The two possible reasons that are associated with this type of spectral behaviour are as follows.

A study on Lake Bogoria - a saline-alkaline eutrophic lake known for supporting algal blooms of cyanobacteria - reported change in colour of the lake from green to brown due to algal die-off ${ }^{8}$. This is a condition of decay of the algal population which leads to increased CDOM (humic acids). This may result in increased absorption in the blue region $(<500 \mathrm{~nm})$. Since it involves decay of algae, concentration of chlorophyll- $a$ also decreases, which leads to increased absorption in the NIR region due to water molecules. The study using Landsat 7 ETM+ data showed that during algal die-off overall reflectance decreases with maximum reflectance in the red region

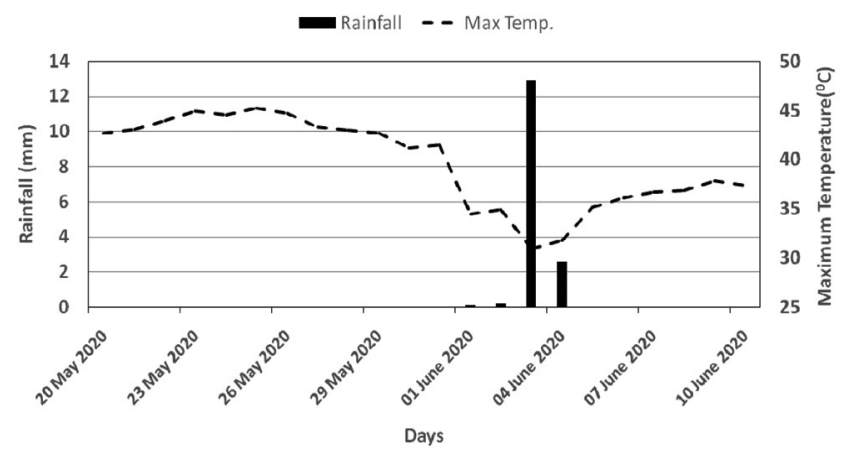

Figure 5. Weather parameters during summer 2020. 


\section{RESEARCH COMMUNICATIONS}

$(665 \mathrm{~nm})$, which explains the brown appearance of the water body ${ }^{8}$.

Prolonged exposure to ultraviolet radiation in calm wind conditions is a possible reason for algal die-off ${ }^{8}$. In addition, dilution due to heavy rainfall is suggested to be linked with such a phenomenon. Figures 5 and 6 show the temporal variation in rainfall and maximum air temperature during summer 2020 and 2019 respectively, obtained from IMD gridded data.

Figure 5 shows that there was $13 \mathrm{~mm}$ rainfall on 3 June 2020 and scanty rainfall on 4 June 2020, days before the lake turned brown ( 5 June) from bright green (31 May). Figure 6 shows that there were rainfall events on 8 and 9 June 2019 of light intensity, just days before when a slight brown-green colour of the lake was observed in the MSI images on 11 June 2019. It should be noted that rainfall events just before the colour change of Lonar lake in 2019 and 2020 had light intensity. Generally, heavy rainfall events are associated with algal die-off. Another important abiotic stress factor that is associated with algal die-off is solar irradiance (and temperature). Figures 5 and 6 show that temperature consistently ranged about $45^{\circ} \mathrm{C}$ for two weeks prior to colour change of the lake during both years, which dropped to $35^{\circ} \mathrm{C}$ in 2020 and to

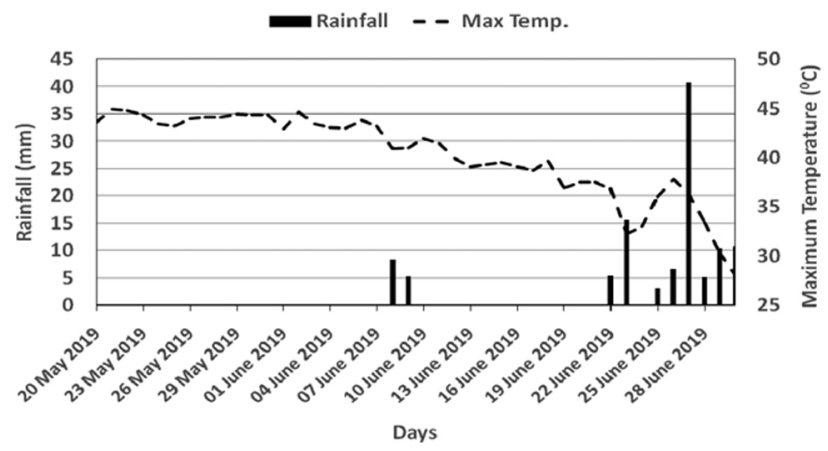

Figure 6. Weather parameters during summer 2019.

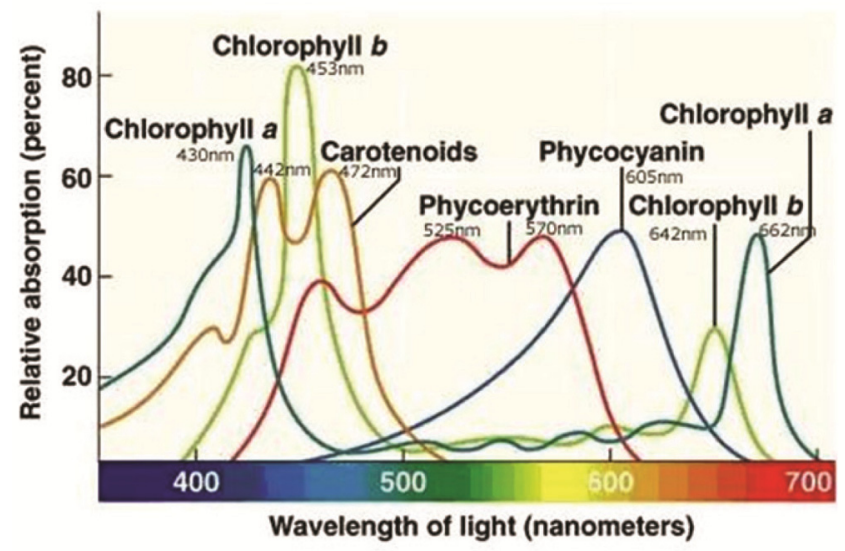

Figure 7. Absorption spectra of various algal pigments. (Source: Algae Research Supply, 2020.) $40^{\circ} \mathrm{C}$ in 2019 . These changes in temperature and radiation (due to clouds) along with rainfall may have caused stress on blooms of algae, if not their complete die-off.

As discussed earlier, Lonar lake is dominated by $S$. platensis, which has carotenes, chlorophyll- $a$ and phycocyanin. Abiotic stresses caused by change in solar irradiance, salinity, temperature and $\mathrm{pH}$ lead to change in the production of biomass and bio-pigment accumulation ${ }^{10}$. For instance, a study reported decreased chlorophyll- $a$ content and increased content of beta-carotene when salinity was increased ${ }^{11}$. Rodríguez et al. ${ }^{12}$ reported increased production of phycobiliproteins (phycoerythrin, phycocyanin, allophycocyanin) with decreasing irradiance. The pigments other than chlorophyll- $a$, such as phycocyanin, beta-carotene and phycoerythrin show unique absorption features. Figure 7 shows the rough regions of absorption by the main pigments found among plants and algae ${ }^{13}$. Spectra of Lonar lake post colour change event show increased absorption in blue (495 nm) and green $(560 \mathrm{~nm})$ regions, which is expected due to dominance of pigments, especially phycoerythrin or carotenoids.

Figure 8 shows the spectral response of Lonar lake during summer 2019. On 27 May and 6 June, the lake appeared green, and had similar spectral shape, except the

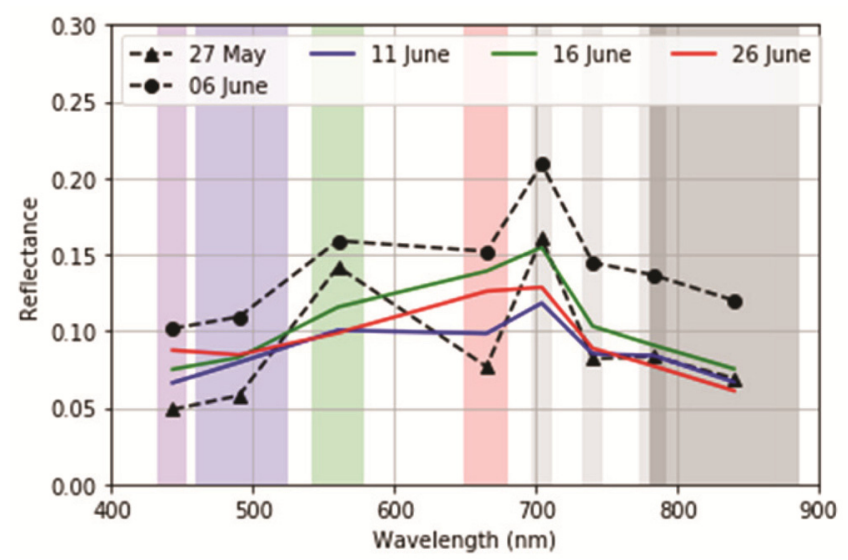

Figure 8. Water spectra of Lonar lake during summer 2019.

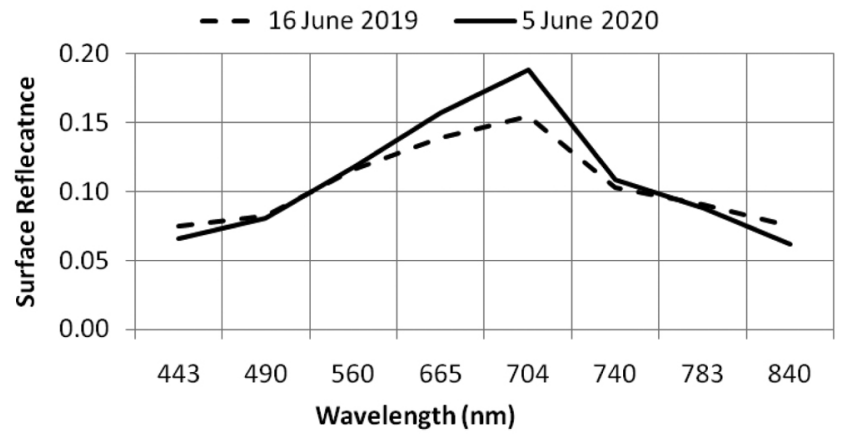

Figure 9. Water spectra of Lonar lake on 16 June 2019 and 5 June 2020 .

CURRENT SCIENCE, VOL. 120, NO. 1, 10 JANUARY 2021 
magnitude of reflectance in Visible-near infrared (VNIR) region. Notably, 6 June had highest reflectance in all the bands because this image was affected by the clouds which increased radiance due to scattering. The water spectra on 11, 16 and 26 June, associated with brown appearance, show distinct spectral response. The spectrum on 11 June shows a flat response in the green and red regions with a small peak in the red-edge region, whereas spectra on both 16 and 26 June show decreased reflectance in the blue $(495 \mathrm{~nm})$ and green $(560 \mathrm{~nm})$ regions. In the absence of chlorophyll- $a$ increased absorption in blue-green and NIR regions causes peak reflectance in the red region, which explains brown appearance of the lake.

Salient features of spectral response of Lonar lake during the colour change process from the satellite data analysis are given below.

(i) The change in colour of the lake from green to brown was observed in 2019 and green-brown-red was observed in 2020.

(ii) The green colour of the lake seems to be due to dominance of chlorophyll- $a$ pigment in the algae population.

(iii) The brown colour of the lake was observed during both the years; however, a distinct red colour was observed in 2020 only.

(iv) The spectral response was similar on 16 June 2019 and 5 June 2020 and on both the days Lonar lake appeared brown (Figure 9).

(v) The spectral response on 26 June 2019 was similar to that on 10 June 2020, when Lonar lake appeared red and was reported in the media. Figure 10 compares spectral response on both the days. An increased absorption of radiation is evident in the $495 \mathrm{~nm}$ blue band in this figure. Absorption in this region indicates presence of carotenoids in the algae population. Notably, this absorption feature is only visible on two days when the lake appeared red in the data.

(vi) Comparison of Lonar lake spectra during summer 2019 and summer 2020 pre and post colour change events, revealed that there is increased absorption of blue $(495 \mathrm{~nm})$ and green $(560 \mathrm{~nm})$ radiation when the lake appeared brown or red. This is plausible because of the presence of pigments such as carotenoids or phycoerythrin. Absorption in the green region (560 nm) is generally caused by phycoerythrin, which is a dominant pigment type found in red algae.

In order to assess whether the colour change phenomenon occurs over a long period, historic data from Landsat-8 OLI and Sentinel MSI sensors were analysed using Google Earth Engine (GEE) platform. Based on the spectral response pattern during the last year, an index is proposed to assess this colour change phenomenon, viz. normalized red-green difference (NRGD) index. This is the difference between reflectance in red and green bands, normalized over sum of the reflectance in the red and green bands. Average value of NRGD index over a small patch of Lonar lake was estimated using all the cloud-free satellite data. The collections of Landsat- 8 OLI and Sentinel MSI sensors available from January 2014 till date under GEE were used. Figure 11 shows the temporal variation of NRGD index of Lonar lake.

It is observed from Figure 11 that most of the time, the NRGD index is negative and the value is around -0.2 , indicating that reflectance in the green band is higher than that in the red band. However, on a few occasions the NRGD index is positive and more than 0.1 , indicating that reflectance in the green band is far less than that in the red band. The analysis showed that a change in colour of the lake was observed thrice during the last week of April-first week of May 2019, mid June 2019, and during the second week of June 2020. Figure 12 shows the satellite images for these dates.

The present study used remote sensing data of MSI sensor on-board Sentinel 2A/2B time-series images to analyse the temporal dynamics of colour change of Lonar lake. It is observed that green colour of the lake, before it turned brown (on 5 June 2020) and red (10 June 2020)

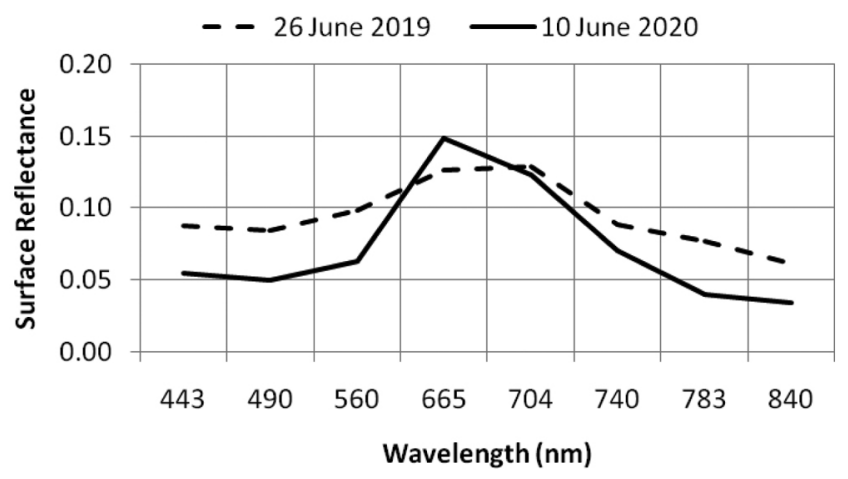

Figure 10. Water spectra of Lonar lake on 26 June 2019 and 10 June 2020 .

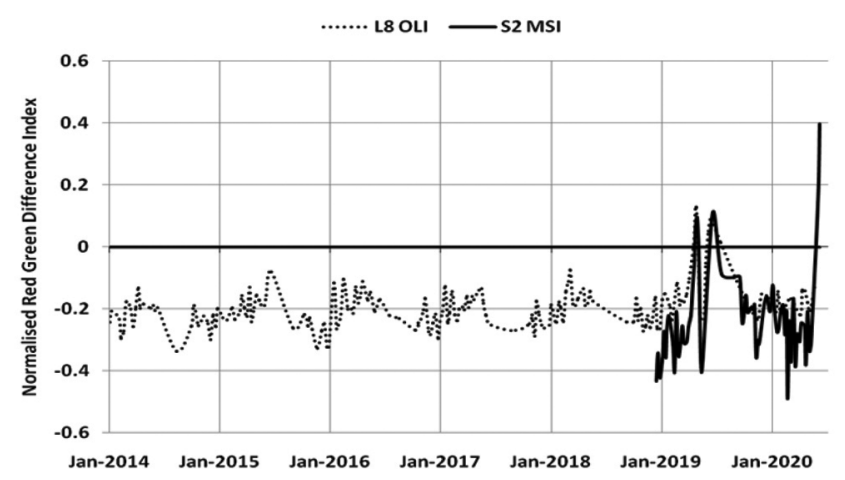

Figure 11. Temporal variation of NRGD index of Lonar lake. 


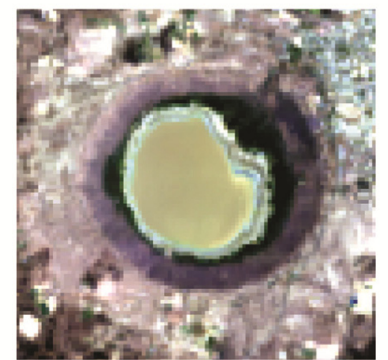

28 April 2019 (L8/OLI)

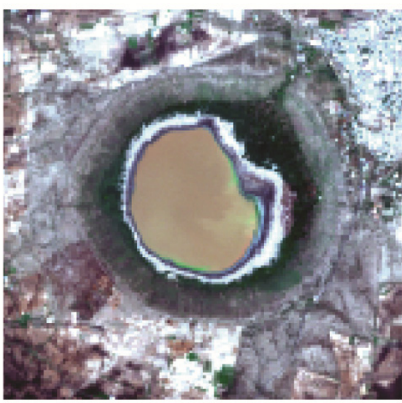

5 June 2020 (S2/MSI)

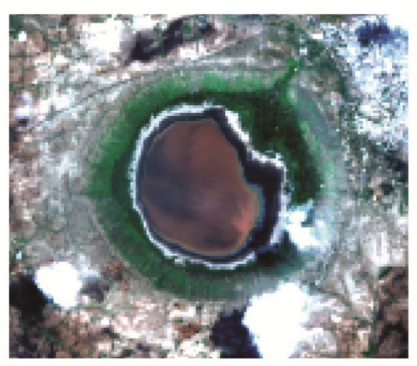

26 June 2019 (S2/MSI)

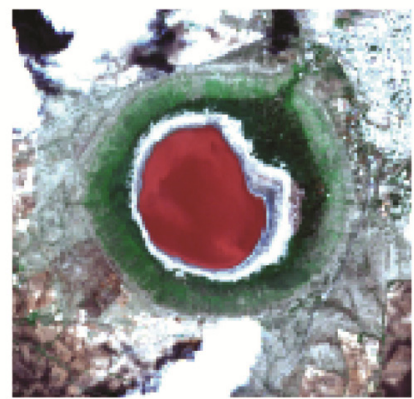

10 June 2020 (S2/MSI)
Figure 12. Natural colour images of high NRGD index values during 2019 and 2020.

was due to dominance of chlorophyll- $a$ present in the algae population of the lake. Similar change of colour was also observed in summer 2019, which was less intense than that observed in 2020. The study examined seemingly possible causes: (1) decay of algal population, which is generally caused by prolonged UV exposure under calm wind conditions, or due to dilution by heavy rainfall events. (2) Dominance of pigments other than chlorophyll- $a$ in response to abiotic stresses. Light rainfall events just before the colour change were observed in 2019 as well as in 2020 in IMD gridded data. However, these events do not appear to cause algal die-off. In addition, drop in temperature was observed during the same period, which along with dilution by rainfall might have caused abiotic stress on blooms of algae. This is seen in the images just before the colour change. It appears that red colour (as seen in the satellite data) of the lake is due to dominance of phycoerythrin and carotenoids, in response to abiotic stress condition experienced by algae population of the lake. As discussed earlier, decreased reflectance in the green band of MSI is possibly due to absorption by phycoerythrin. In addition, on 26 June 2019 and 10 June 2020, when intense red colour was observed in Lonar lake, there was less reflectance in the blue region $(495 \mathrm{~nm})$ compared to its neighbouring bands. This feature in the spectra was not observed on previous days, even when the colour of the lake appeared brown. If it is assumed to be an absorption feature of a pigment, most likely it would be carotenoids. Though cause of stress on algae population is not known and needs to be precisely identified by field surveys, the change in colour of Lonar lake appears to be caused by pigments like phycoerythrin and carotenoids. However, this observation needs to be verified through further analysis.

1. Lonar lake's change of colour leaves people surprised, experts feel salinity and algae are the reasons. The Economic Times, retrieved 17 June 2020; https:/economictimes.indiatimes.com/magazines/ panache/lonar-lakes-change-of-colour-leaves-people-surprisedexperts-feel-salinity-and-algae-are-the-reasons/articleshow/76315$427 . \mathrm{cms}$

2. Change in colour of Lonar lake: Bombay HC convenes special sitting to issue directions to authorities. Hindustan Times, retrieved 17 June 2020; https://www.hindustantimes.com/mumbainews/change-in-colour-of-lonar-lake-bombay-hc-convenes-specialsitting-to-issue-directions-to-authorities/story-N4ytTBe9P4A27MmloAqnjO.html

3. Milton, D. J., Dube, A. and Gupta, S. S., Deposition of ejecta at Lonar Crater. Meteoritics, 1975, 10, 456.

4. Basavaiah, N. et al., Physicochemical analyses of surface sediments from the Lonar Lake, central India - implications for palaeoenvironmental reconstruction. Fundam. Appl. Limnol., 2014, 184/1, 51-68.

5. Badve, R. M., Kumaran, K. P. N. and Rajshekhar, C., Eutrophication of Lonar Lake, Maharashtra. Curr. Sci., 1993, 65, 347-351.

6. Waghmode, A. and Kumbhar, R., Study of blue-green algae from Lonar Lake. Indian J. Fundam. Appl. Life Sci., 2016, 6(2), 69-73.

7. Ciferri, O., Spirulina, the edible microorganism. Microbiol. Rev., 1983, 47(4), 551-578.

8. Tebbs, E., Remedios, J. and Harper, D., Remote sensing of chlorophyll- $a$ as a measure of cyanobacterial biomass in Lake Bogoria, a hypertrophic, saline-alkaline, flamingo lake, using Landsat ETM +. Remote Sensing Environ., 2013, 135, 92-106.

9. Jensen, J. R., Remote Sensing of the Environment: An Earth Resource Perspective, Pearson Prentice Hall, Upper Saddle River, 2007, 2nd edn

10. Sharma, G., Kumar, M., Ali, M. I. and Jasuja, N. D., Effect of carbon content, salinity and $\mathrm{pH}$ on Spirulina platensis for Phycocyanin, Allophycocyanin and Phycoerythrin Accumulation. Microb. Biochem. Technol., 2014, 6(4), 202-206.

11. Ben-Amotz, A. and Avron, M., On the factors which determine massive $\beta$-carotene accumulation in the halotolerant alga Dunaliella bardawil. Plant Physiol., 1983, 72(3), 593-597.

12. Rodríguez, H., Rivas, J., Guerrero, M. G. and Losada, M., Enhancement of phycobiliprotein production in nitrogen-fixing cyanobacteria. J. Biotechnol., 1991, 20(3), 263-270.

13. Algae Research Supply, Lighting for algae cultures. Retrieved 25 June 2020; https://algaeresearchsupply.com/pages/lighting-foralgae-cultures

Received 9 July 2020; revised accepted 5 November 2020

doi: $10.18520 / \mathrm{cs} / \mathrm{v} 120 / \mathrm{i} 1 / 220-226$ 